\title{
INFLUÊNCIA DA AVERSÃO À TRAIĈ̃̃ SOBRE 0 COMPORTAMENTO DO CONSUMIDOR: EXPERIMENTOS COM PRODUTOS DE SEGURANÇA
}

INFLUENCE OF BETRAYAL AVERSION ON CONSUMER BEHAVIOR: EXPERIMENTS WITH SAFETY PRODUCTS

\section{Tharcisio A. Caldeira}

tharcisio.caldeira@ifsudestemg.edu.br

Instituto Federal do Sudeste de Minas Gerais, Rio Pomba/MG, BRASIL

\section{Andréia A. Albino}

andreia.albino@ifsudestemg.edu.br

Instituto Federal do Sudeste de Minas Gerais, Rio Pomba/MG, BRASIL

\section{Jorge Ferreira Brantes}

jorge.brantes@gmail.com

Pontifícia Universidade Católica do Rio de Janeiro, Rio de Janeiro, RJ, BRASIL

\section{T. Diana L. Van Aduard de Macedo-Soares}

tdiana.vanaduardmacedosoares@gmail.com

Pontifícia Universidade Católica do Rio de Janeiro, Rio de Janeiro, RJ, BRASIL

\section{Resumo}

Este artigo investigou a influência da aversão à traição no comportamento dos consumidores de produtos de segurança, propondo uma extensão ao trabalho de Gershoff e Koehler (2011). A literatura investigada discute o processo de tomada de decisão diante de condições incertas, a aversão ao risco e a aversão à traição. Foram realizados três experimentos com 525 universitários que escolheram entre dois carros idênticos equipados com diferentes air bags. Dentre os participantes, alguns eram aleatoriamente expostos à possibilidade de falha do air bag. Os experimentos verificaram se a escolha dos consumidores poderia ser influenciada por: tipo de traição; destinatário do produto (próprio respondente ou terceiros) e exposição a campanhas de direção defensiva. Os resultados evidenciaram a existência de aversão quando os indivíduos eram expostos à possibilidade de traição de um produto de segurança e que tal aversão levou os respondentes a escolherem de forma irracional os produtos de segurança.

Palavras-chave: Comportamento do Consumidor. Tomada de Decisão. Risco. Aversão à Traição. Produtos para Segurança.

\begin{abstract}
This article investigated the influence of betrayal aversion on consumer behavior regarding safety products, expanding Gershoff and Koehler's (2011) work. The investigated literature discusses the decision-making process in the face of uncertain conditions, risk aversion and betrayal aversion. Three experiments were conducted with 525 students who chose between two identical cars equipped with different air bags. Among the participants, some were randomly exposed to the possibility of air bag failure. The experiments verified if consumer's choice was influenced by: type of betrayal; product recipient (own respondent or other people) and exposure to defensive driving campaigns. The results showed the existence of aversion when individuals were exposed to the possibility of betrayal by a security product and that such aversion led respondents to choose irrationally security products.
\end{abstract}

Keywords: Consumer Behavior. Decision Making. Risk. Betrayal Aversion. Safety Products. 


\section{Introdução}

A tomada de decisão de um consumidor quanto à escolha de um produto pode envolver diversos fatores, que podem ser de natureza econômica, cultural ou legal, entre outros. No caso de determinados produtos, um dos fatores que pode afetar a escolha do consumidor diz respeito à segurança que o produto oferece. Por exemplo, a escolha de um veículo pode sofrer alterações pelo fato deste possuir - ou não acessórios que prometem mais segurança, como air bags ou freios ABS.

Apesar de alguns modelos social-cognitivos indicarem que as decisões de consumo são determinadas pelo processamento racional das informações disponíveis acerca de um determinado produto, conforme sugerido por Torres e Allen (2009), muitas vezes os consumidores administram grandes cargas de emoção em suas escolhas. Desta forma, a decisão sobre a escolha de produtos voltados para a segurança pessoal, por exemplo, pode ser influenciada e até mesmo definida com base em elementos emocionais (DROLET; LUCE, 2004). Isto ocorre porque os critérios racionais podem não ser eficazes em determinadas situações. Por exemplo, a análise custo/benefício de produtos destinados à segurança não é algo simples de se fazer. Gershoff e Koehler (2011) explicam que é difícil estimar os riscos de insucesso destes produtos, uma vez que eles dependem de outras condições para funcionarem perfeitamente. No caso de freios $A B S$, por exemplo, eles dependem das condições da estrada e da velocidade do veículo, entre outros fatores, para assegurarem maior segurança ao usuário.

A adoção de critérios apenas racionais para a escolha de produtos de segurança fica ainda mais complexa se considerarmos que estes produtos apresentam probabilidade de falha. Um exemplo seria a escolha de modelos diferentes de air bags, visto que estes têm uma pequena probabilidade de funcionar de forma indevida ou até mesmo não funcionar (MEYER; FINNEY, 2005). Tal situação corresponde à traição por parte dos produtos para segurança, um dos temas centrais deste estudo.

Koehler e Gershoff (2003) iniciaram uma análise do comportamento das pessoas verificando como estas respondem à possibilidade de traição por parte de produtos de segurança em uma variedade de contextos. Verificaram que os consumidores consideram o risco de traição ao escolher entre os dispositivos de segurança e ainda explicaram que as fortes emoções negativas em relação a uma traição em potencial podem levar as pessoas a assumir riscos imprudentes (KOEHLER; GERSHOFF, 2003). De acordo com Andrade e Ariely (2009), as emoções são específicas e resultam de breves sentimentos subjetivos, os quais costumam ter uma causa identificável. Os referidos autores ainda explicam que, apesar das diferenças conceituais, a emoção e o humor possuem potencial para influenciar o julgamento e tomada de decisão. Segundo Hawkins e Mothersbaugh (2010), os tipos de pensamentos e a habilidade de pensar racionalmente podem ser afetados pela intensidade emocional.

Koehler \& Gershoff (2003) sugerem que existe uma forte associação entre a aversão à traição e a presença de emoções negativas, de modo que uma análise dessa associação se faz necessária para avançar na compreensão de alguns fatores que interferem na escolha das pessoas para este tipo de produto.

Nos estudos realizados por Koehler e Gershoff em 2003 e em 2011, foi possível verificar que emoções negativas podem levar os indivíduos a fazer escolhas tendenciosas e, por vezes, irracionais, em função da aversão à traição. Além disso, estes estudos mostraram que tal aversão "pode ser reduzida ou eliminada através da introdução de fatores que atenuem a emoção negativa que os consumidores sentem" (KOEHLER; GERSHOFF, 2003, p. 3).

Diante do exposto, a presente pesquisa teve como objetivo realizar uma extensão do estudo de Gershoff e Koehler (2011), a fim de identificar se a informação de possibilidade de falha (traição) em um produto de segurança poderia levar o consumidor a tomar uma decisão considerada irracional, em função da aversão à traição. Para tanto, três experimentos foram realizados no Brasil em abril de 2013, tendo como objeto de estudo a escolha entre carros com diferentes tipos de air bags.

O artigo é dividido em cinco partes, a saber: referencial teórico geral que aborda a tomada de decisão sob condições de incerteza e a aversão ao risco bem como sua influência na escolha do consumidor; descrição de cada um dos três experimentos desenvolvidos - sendo que cada descrição inclui suportes teóricos específicos, forma de coleta e tratamento dos dados, e descrição e análise dos resultados - bem como considerações finais acerca dos resultados da pesquisa. 


\section{Referencial Teórico}

\section{A tomada de decisão sob condições de incerteza}

Em um processo decisório, a qualidade e quantidade das informações disponíveis para o consumidor se mostram imprescindíveis para diminuir a incerteza característica do momento. No entanto, geralmente o consumidor não dispõe das informações necessárias para estimar as consequências das decisões com confiabilidade, de forma que tal processo geralmente se dá sob condições de incerteza.

Diversos estudos sobre o comportamento do consumidor indicam que o consumo é impulsionado fundamentalmente pela constante busca de satisfação das necessidades. Em função destas necessidades, o consumidor demanda determinados produtos ou serviços, criando expectativas sobre seu desempenho. Uma vez que a confiança, segundo Koehler e Gershoff (2003), se constitui em um estado psicológico baseado em expectativas positivas em relação a um indivíduo, objeto ou comportamento, pode-se inferir que a confiança em determinados produtos depende da sua capacidade de cumprir as expectativas dos consumidores. Para tanto, as empresas devem não apenas se preocupar em fornecer produtos que atendam às expectativas dos consumidores, mas também devem se preocupar em elaborar estratégias adequadas de comunicação, com o objetivo de transmitir informações suficientes para despertar a sensação de confiança no consumidor.

A esse respeito, diversos autores pesquisaram o comportamento dos tomadores de decisão diante de um cenário de incerteza, com resultados sugerindo a existência de dois sistemas envolvidos na tomada de decisão: um emocional e um racional. Tais sistemas coexistem e, dependendo das circunstâncias, algum deles assume papel mais preponderante. Ao passo que o sistema emocional cria, de forma rápida e automática, impressões acerca dos estímulos recebidos, o sistema racional analisa as impressões geradas pelo sistema emocional, com base em um sistema de julgamento mais deliberativo (EPSTEIN et al., 1996; SLOMAN, 1996). No sistema racional, informações sobre produtos, preços e marcas "são analisadas e conduzem a intenções individuais que resultariam no comportamento de escolha e compra" (TORRES; ALLEN, 2009).

Slovic e Peters (2006) acrescentam que as pessoas interpretam a realidade de duas maneiras distintas.
Uma seria "intuitiva, automática, natural, não verbal e experimental" (EPSTEIN, 1994, p. 710) e daria importância à presença de sentimentos agradáveis ou desagradáveis dado que estes teriam potencial para influenciar a tomada de decisão. A outra seria mais analítica, precisamente, "deliberativa, verbal e racional". Slovic e Peters (2006, p. 322) observam que "embora a análise seja algo importante para a tomada de decisão, a confiança no afeto é geralmente uma maneira mais rápida, mais fácil e mais eficiente para navegar em um mundo complexo, incerto, e às vezes perigoso". Por isso, "muitos estudos atribuem ao afeto um papel direto e primário no ato de motivar o comportamento das pessoas" (SLOVIC et al., 2005, p. 35). Em um cenário onde as informações não estão totalmente disponíveis, quanto maior a incerteza presente - e consequentemente o risco - maior a influência do sistema emocional sobre a tomada de decisão.

Adicionalmente, Rottenstreich e Kivetz (2006) explicam o escopo de duas correntes teóricas sobre a tomada de decisões. Afirmam que a maioria das teorias que analisam a forma como as pessoas tomam decisões é probabilística, sugerindo que, na tomada de decisões as pessoas julgam a probabilidade de eventos relevantes ocorrerem. No entanto, defendem que sejam adotadas abordagens não probabilísticas para a tomada de decisão, como por exemplo, àquelas que consideram regras ou lógicas que surgem a partir de um cenário ou de uma construção histórica ou emergem de um fator afetivo. Assim, quando surge uma situação de risco, ainda que pouco significativa do ponto de vista estatístico, as pessoas podem deixar de analisar corretamente a possibilidade de eventos significativos ocorrerem, privilegiando fatores mais carregados de emoção.

\section{A Aversão ao Risco e sua Influência na Escolha do Consumidor}

A aversão ao risco, segundo Kahneman e Tversky (1979) e Bohnet et al. (2008), desempenha um papel central na teoria econômica. Por se tratar de algo fundamentalmente relacionado com as escolhas dos consumidores, tem sido estudada por diferentes perspectivas, por exemplo, a da psicologia (SLOMAN, 1996; SLOVIC; PETERS, 2006) ou a do marketing (ROSELIUS, 1971). Diferenças de gênero são observadas no que concerne ao ato de lidar com o risco. É o caso de Borghans et al. (2009), 
que verificaram que mulheres são mais avessas ao risco do que homens. Dohmen et al. (2010), por sua vez, observaram que pessoas com menor habilidade cognitiva são significativamente mais avessas ao risco.

Chu e Chintagunta (2011) investigaram a percepção dos consumidores acerca de garantias de produtos. Um dos resultados do seu estudo revelou que quando as pessoas possuíam diferentes percepções de risco, o fornecimento de garantias com diferentes durações principalmente contra falhas dos produtos - tinha um impacto nas percepções dos clientes.

A possibilidade de falhas dos produtos representa um tipo de risco que os consumidores enfrentam quando da escolha de produtos. Considerando que produtos podem simplesmente não funcionar ou funcionar de modo inadequado, tem-se aí uma traição por parte do produto. A traição se constitui em algo que viola a expectativa das pessoas e que, por consequência, prejudica a confiança. Por isso, em diversos campos, como nas relações no local de trabalho, por exemplo, as experiências relacionadas com a traição costumam ser carregadas de sentimentos negativos (MORRISON; ROBINSON, 1997).

De acordo com Sunstein (2005), a traição da confiança pode produzir elevada indignação, ou seja, as pessoas ficarão mais irritadas quando ocorre uma situação de traição por parte de alguém ou algo conhecido do que quando a mesma situação parte de algo ou alguém estranho, no qual não se depositou confiança. O autor procura explicar tal fenômeno destacando que a traição da confiança é um mal independente, ou seja, indica que, além do evento ruim que ocorre, a causa do referido evento também significa algo decepcionante para o indivíduo vitimado.

Considerando a traição como mal independente, Gershoff e Koehler (2011) explicam que existe nas pessoas uma tendência a reagir a ações prejudiciais mais fortemente do que reagiriam a omissões igualmente prejudiciais. Nesse sentido, as pessoas estariam dispostas a assumir maiores riscos globais, desde que acreditassem estar evitando possibilidades de traição (KOEHLER; GERSHOFF, 2003). Para Raghunathan e Pham (1999, p. 58), "estados afetivos negativos podem influenciar as decisões moldando os motivos dos tomadores de decisão". As pessoas estabelecem relações de confiança assimétricas com vários produtos e objetos, desconsiderando até o fato de que a confiança, e, por consequência, a traição, só seria realmente considerada traição se estiver presente a intenção, algo que não é possível quando tratamos de produtos (KOEHLER; GERSHOFF, 2003).

Por sua vez, Prentice e Koehler (2003) argumentam que é possível observar uma tendência nas pessoas a reagirem a maus resultados que surgem de circunstâncias anormais com intensidade muito maior do que reagiriam a resultados igualmente ruins que surgiriam de circunstâncias mais comuns. Nessa ‘relação' estabelecida com produtos, exemplificando a primeira situação, teríamos o caso de um dispositivo de segurança com o potencial para se comportar de forma anormal, podendo desempenhar um papel ativo no causar danos. Acredita-se, então, que esse comportamento anormal por parte do dispositivo de segurança pode provocar uma reação mais intensa, e, consequentemente, pode-se pressupor que a aversão a esse tipo de comportamento anormal seja muito superior a uma situação de risco que seja considerada mais corriqueira.

Slovic et al. (2005, p. 38) explicam "porque as preocupações da sociedade sobre perigos - como àqueles relacionados com a energia nuclear, por exemplo - não diminuem quando são fornecidas informações sobre as mínimas probabilidades de ocorrerem as consequências temidas de tais riscos". Tal argumento parece reforçar a aversão à traição.

Por outro lado, Aimone e Houser (2011; 2013), ao estudarem benefícios da aversão à traição, argumentam que a grande maioria dos estudos busca evidências para confirmar que a aversão à traição dificulta a confiança e desestimula a cooperação, enquanto nenhum estudo procura identificar benefícios na aversão à traição. Com o intuito de fornecer uma estrutura eficaz que auxilie na compreensão dos efeitos da aversão à traição no comportamento humano, os autores realizaram um experimento nos moldes de um jogo que envolvia diversas transações monetárias, onde as pessoas (denominadas investidores e administradores) podiam escolher entre confiar, não confiar, trair ou não trair em relação aos demais jogadores. Os investidores poderiam escolher se queriam ou não ser expostos ao conhecimento da traição. Um importante resultado do experimento foi que "os investidores geralmente estão dispostos a assumir os riscos monetários de uma aposta de confiança, mas muitos não estão dispostos a assumir os riscos emocionais" decorrentes dessa possibilidade de traição (ibid., p. 2). 
Roselius (1971) estudou o fato de que, quando um indivíduo percebe a existência de risco em uma compra, ele pode adotar diferentes estratégias para reduzir tal risco. Nesse sentido, argumenta que, uma vez que diversos métodos podem ser ofertados ao consumidor a fim de reduzir o risco, o comerciante desconhece qual dos métodos pode ser o mais indicado para seu produto. Seu trabalho relacionou os principais tipos de perda (de tempo, financeira, de segurança e de ego) aos principais tipos de redutores de risco utilizados pelos consumidores, de modo que os resultados indicaram que determinados métodos apresentam índices de preferência semelhantes, para todos os tipos de perda e para todos os níveis de percepção ao risco analisados (fidelidade à marca, testes de empresas privadas, endossos, compra do modelo mais caro e garantias de reembolso), ao passo que determinados métodos apresentam resultados que variam de acordo com o tipo de perda envolvida na compra e com o nível de percepção do risco. No caso de perda de segurança, por exemplo, há uma maior preferência pelos testes governamentais em relação aos demais tipos de perda. Quando o consumidor possui maior percepção do risco, essa preferência pelos testes governamentais é ainda maior. Assim, o autor defende que os comerciantes devem focar nos métodos de redução de risco que mais se adequarem à natureza de seus produtos e ao tipo de consumidor que possuem.

Acredita-se que, especialmente no caso de produtos para segurança, os quais costumam demandar escolhas complexas, torna-se necessário compreender quais fatores despertam mais ou menos confiança nos consumidores, de modo a gerar subsídios para a escolha do conteúdo da comunicação das empresas com relação aos benefícios e riscos de seus produtos. Cabe ressaltar que este artigo não pretende ser prescritivo - pois existem muitos outros fatores envolvidos, por exemplo, as questões de ética na comunicação - se limitando à tentativa de ampliação da compreensão do processo de tomada de decisão de compra.

\section{Descrição dos métodos utilizados}

As hipóteses levantadas na presente pesquisa foram testadas por meio de experimentos que, segundo Malhotra (2011), são amplamente utilizados em pesquisas que investigam relações de causa e efeito no comportamento do consumidor. Experimentos, em geral, se caracterizam por ser um método de pesquisa no qual uma mudança controlada é imposta ao ambiente, de forma que seja possível observar a influência desta mudança sobre outras variáveis (REMENYI et al., 1998). Além disso, pode-se afirmar que a presente pesquisa é composta por três estudos de grupos estáticos, posto que os respondentes não são selecionados aleatoriamente e que, em cada estudo, tanto o grupo experimental (exposto às mudanças controladas) quanto o grupo de controle (não exposto) são observados somente após às mudanças ambientais. (MALHOTRA, 2011)

No caso dos três experimentos realizados nesta pesquisa, as mudanças controladas dizem respeito à disponibilidade de determinadas informações referentes aos produtos de segurança. Desta forma, foi possível identificar se o comportamento dos consumidores de produtos de segurança foi significativamente influenciado pelo acesso às diferentes informações contidas nos três experimentos.

Para verificar estatisticamente a influência das mudanças no ambiente, foram realizadas Análises de Variância - ANOVA. Segundo Black (2009), a ANOVA pode ser utilizada para determinar diferenças estatísticas entre grupos. No caso da presente pesquisa, os testes ANOVA buscaram verificar diferenças entre o grupo experimental e o grupo de controle de cada estudo, no que tange à escolha de consumo de produtos de segurança. Os próximos tópicos descrevem detalhadamente a mudança controlada imposta ao grupo experimental de cada estudo, bem como os resultados decorrentes de cada mudança.

\section{Estudo 1 - Tipo de Traição}

Os tipos de traição que são considerados neste estudo serão ilustrados por meio do equipamento air bag, que é um dispositivo de segurança que tem também potencial para provocar danos de três maneiras distintas (descritas a seguir). Em todos os casos, o produto estaria violando as expectativas dos consumidores. Assim sendo, os air bags são utilizados neste artigo como exemplos de dispositivos de segurança que podem causar ou permitir danos de diversas maneiras. São três as possibilidades de falhas em tais produtos:

i. Podem tornar-se agentes de danos diretamente - como quando um air bag abre 
com tal força que mata ocupantes de um carro, proporcionando ativamente o dano.

ii. Podem deixar de proporcionar a proteção esperada - sendo responsável pelo dano de maneira passiva.

iii. Podem atuar como deveriam e ainda ser agentes de dano devido à falha em outras partes do sistema - se uma coluna de direção com defeito move o air bag para mais perto do motorista e o machuca. Nesse caso, o dispositivo de segurança é indiretamente responsável pelo dano. Como este tipo de falha não envolve danos ativos nem situações de extrema anormalidade, pode ser gerada menos emoção negativa e, portanto, uma menor aversão a esses tipos de falha potencial (Gershoff \& Koehler, 2011).

Groeppel-Klein et al. (2010) sugerem que as emoções podem influenciar as decisões para uma determinada direção, antes que qualquer pensamento consciente ocorra.

De acordo com Koehler e Gershoff (2003, p. 2) "traições podem resultar de ações e inações iguais", podendo, no entanto, ocorrer variação no entendimento das pessoas e na forma como elas respondem a traição.

Gershoff e Koehler (2011) defendem que a presença de emoções negativas varia de acordo com o tipo de traição que o dispositivo de segurança possa causar, ou seja: i) se um air bag causa a morte das pessoas ativamente, reside neste fato uma clara violação das expectativas do consumidor; ii) se o air bag simplesmente não funciona quando deveria, existe também uma violação das expectativas do consumidor, mas, aparentemente, não tão intensa quanto à violação percebida no primeiro caso; iii) se o dispositivo de segurança funciona normalmente, mas em alguma situação provoca algum dano devido à falha em outras partes do sistema existe um reduzido sentido de que o dispositivo violou expectativas decorrentes da traição interpretada como indireta.

Diante dos tipos de traição que os produtos para segurança podem apresentar, o Estudo 1 pretendeu testar a hipótese seguinte:

$$
\mathrm{H}_{1}: \quad \text { A preferência por air bags não }
$$

é afetada pela informação a respeito da possibilidade de alguma forma de traição.

\section{Coleta e Tratamento dos Dados}

A amostra do Estudo 1 - extraída por conveniência foi composta por 154 estudantes de diversos cursos de uma instituição de ensino superior no Rio de Janeiro. Durante a coleta dos dados, todos os participantes foram alertados de que a pesquisa não tinha objetivo de venda de produtos e que os dados obtidos seriam trabalhados de forma agregada, sem nenhum tipo de exposição do respondente.

A coleta de dados iniciou-se com a escolha, por parte dos participantes, entre dois automóveis idênticos equipados com air bags diferentes. Para o carro A idêntico em todos os grupos - os participantes foram informados de que, em caso de acidentes, havia uma chance de $2 \%$ de morte do motorista, devido ao acidente. Esta descrição fez do "carro A" a opção com o maior risco global de morte.

As informações referentes ao carro B variavam de acordo com a condição experimentada por cada grupo:

- Grupo 1 (Grupo de Controle): o carro B apresenta, em caso de acidentes, uma chance de $1 \%$ de morte do motorista, devido ao acidente. Cabe ressaltar que o grupo de controle - onde não é apresentado nenhum risco de traição não foi apresentado no estudo similar conduzido por Gershoff e Koehler (2011);

- Grupo 2 (Traição Ativa): o carro B apresenta, em caso de acidentes, uma chance de $1 \%$ de morte do motorista, devido ao acidente. Além disto, existe um risco adicional de 1 chance em 10.000 $(0,01 \%)$ do air bag falhar, de forma que, quando acionado, o mesmo abriria com tanta força que levaria o motorista à morte;

- Grupo 3 (Traição Indireta): o carro B apresenta, em caso de acidentes, uma chance de $1 \%$ de morte do motorista, devido ao acidente. Além disto, existe um risco adicional de 1 chance em 10.000 
$(0,01 \%)$ de, com o impacto, a barra de direção se deslocar, empurrando fortemente o air bag na direção do motorista, levando-o à morte;

- Grupo 4 (Traição Passiva): o carro B apresenta, em caso de acidentes, uma chance de 1\% de morte do motorista, devido ao acidente. Além disto, existe um risco adicional de 1 chance em $10.000(0,01 \%)$ do motorista morrer em função do air bag simplesmente não ter funcionado no momento do acidente.

É importante ressaltar que, apesar dos riscos associados à traição do produto de segurança, o risco global do carro B - 1,01\%, para os Grupos 2, 3 e 4 - ainda é menor que o risco envolvido na escolha pelo carro A.

Foi aplicado um questionário para cada participante, com a descrição dos modelos de air bag - que variava de acordo com o grupo analisado, como citado anteriormente - composto de uma única pergunta. O enunciado da pergunta indicava que as pessoas deveriam escolher entre dois automóveis idênticos, equipados com air bags diferentes. Em seguida, eram descritas as características dos dois air bags e então era solicitado aos respondentes que fizessem sua escolha entre o automóvel equipado com o air bag 1 e o automóvel equipado com o air bag 2. As opções de resposta foram apresentadas em uma escala tipo Likert de 7 pontos, onde os pontos extremos indicavam: 1 - "Definitivamente prefiro opção A" e 7 - "Definitivamente prefiro a opção B".

A partir dos questionários, foi realizada uma One-Way ANOVA para identificar diferenças de comportamento entre os grupos. Além disso, o teste de Tukey-Kramer foi utilizado para identificar, em caso de diferenças significativas, quais grupos apresentavam tais diferenças.

\section{Análise dos dados e apresentação dos resultados}

Os resultados da One-Way ANOVA revelaram diferenças significativas na escolha do tipo de air bag, de acordo com a disponibilidade da informação acerca da falha do produto, levando à rejeição da hipótese $\mathrm{H}_{1}(\mathrm{~F}(3$, $150)=11,044 ; p=0,000)$. Os indivíduos que não foram informados a respeito da possibilidade de traição indicaram preferência pela opção mais segura. Por outro lado, diante da informação da possibilidade de traição, a preferência pela opção mais segura diminuiu, de forma que a aversão à traição conduzia a uma escolha menos segura, conforme a Figura 1:

Figura 1. Preferência pela opção de air bag mais segura, de acordo com o tipo de informação a respeito da traição

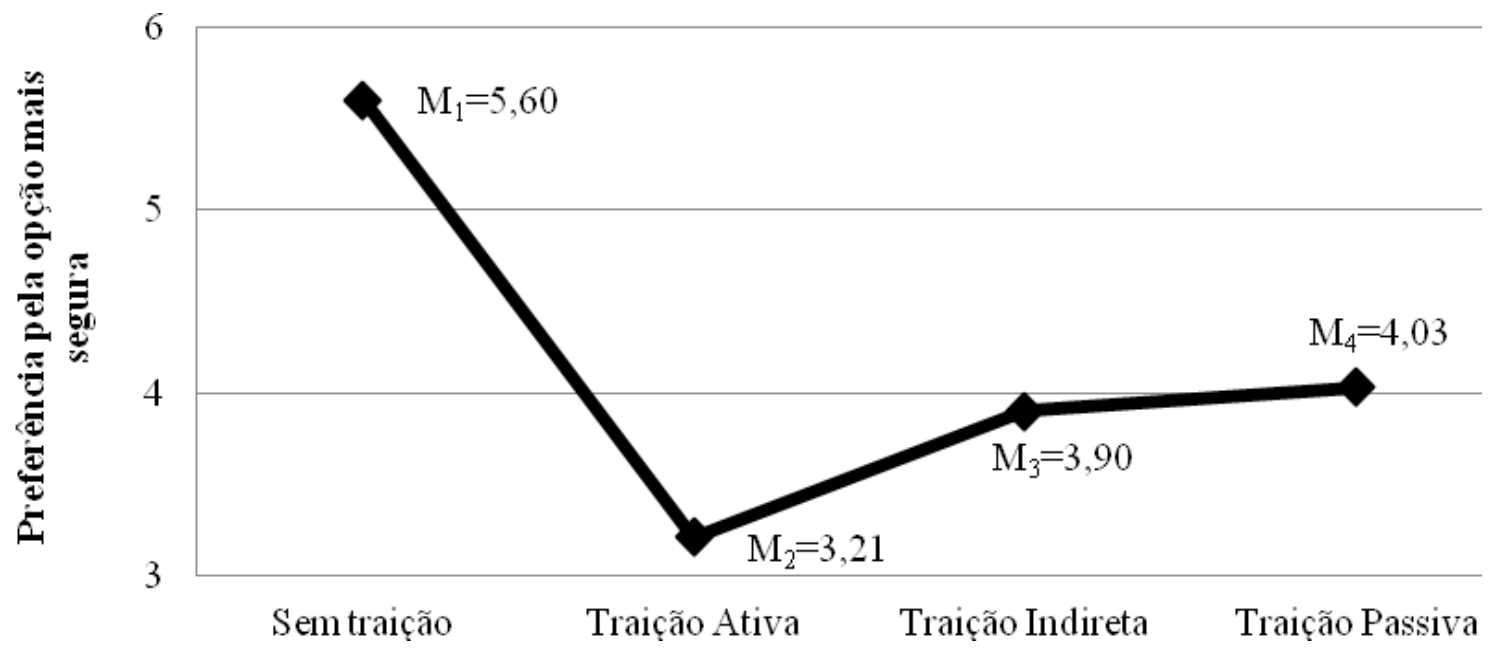


No entanto, a Tabela 1 - que exibe os resultados do teste de Tukey-Kramer - indica a inexistência de diferenças significativas entre os tipos de traição. Concluiu-se que, apesar de todos os tipos de traição afetarem a preferência por air bags - levando os indivíduos a realizarem uma escolha irracional - o tipo de traição não interferiu significativamente na magnitude deste efeito.

Tabela 1. Teste de Tukey-Kramer para comparações de múltiplos grupos

\begin{tabular}{ccccc}
\hline Grupo 1 & Grupo 2 & Limite Inferior IC & Limite Superior IC & p-valor \\
\hline \multirow{3}{*}{ Sem traição } & Traição Ativa & 1,2682 & 3,5108 & 0,000 \\
& Traição Indireta & 0,5932 & 2,8068 & 0,001 \\
& Traição Passiva & 0,4351 & 2,7094 & 0,002 \\
\hline \multirow{2}{*}{ Traição Ativa } & Traição Indireta & $-1,8108$ & 0,4318 & 0,383 \\
& Traição Passiva & $-1,9685$ & 0,3340 & 0,257 \\
\hline \multirow{2}{*}{ Traição Indireta } & Traição Passiva & $-1,2649$ & 1,0094 & 0,991 \\
\hline
\end{tabular}

Estes resultados diferem dos encontrados por Gershoff e Koehler (2011), que encontraram diferenças significativas entre os tipos de traição, de tal forma que a traição ativa gerava maior aversão que a traição passiva que, por sua vez, gerava maior aversão que a traição indireta. Retomando a discussão de (PRENTICE; KOEHLER, 2003), na qual os autores afirmam que pessoas podem reagir de diferentes maneiras perante diferentes tipos de traição, tal fato não foi verificado neste experimento.

\section{Estudo 2 - Destinatário do Produto de Segurança}

Segundo Gershoff e Koehler (2011, p. 8), "as pessoas que dão bons conselhos muitas vezes têm dificuldades em seguir esses mesmos conselhos em suas próprias vidas”.

De acordo com Rottenstreich e Kivetz (2006, p. 2) "quando as pessoas são influenciadas por fortes reações emocionais, muitas vezes ignoram a probabilidade de eventos relevantes", de modo que é possível inferir que a escolha de um produto para uso próprio possa despertar maiores emoções - e consequentemente afetar mais a escolha por um produto - do que a escolha de um produto para um desconhecido.

Quando as pessoas fazem escolhas para outras pessoas, tais escolhas podem ser mais neutras ao risco do que as escolhas que as pessoas fazem para si (FARO; ROTTENSTREICH, 2006). A este fenômeno, dá-se o nome de "lacuna de empatia": as pessoas subestimam o impacto das considerações emocionais para estranhos, mas não para si mesmos.

Gershoff e Koehler (2011) partiram do pressuposto de que quando fazem escolhas para pessoas desconhecidas, as pessoas agem de forma mais despreocupada. Os autores acreditam que "esta técnica irá diminuir as emoções negativas normalmente vividas por aqueles que contemplam opções de traição e aumentar a preferência pela opção de menor risco à segurança global" (GERSHOFF; KOEHLER, 2011, p. 8). Concluiram que se existe uma lacuna de empatia quando escolhemos produtos para outras pessoas, a aversão à traição poderia ser reduzida ao solicitar tomadores de decisão que escolham pensando que os produtos seriam para uso de pessoas estranhas.

Diante disto, no Estudo 2 foram testadas as seguintes hipóteses:

$\mathrm{H}_{2}$ : A preferência por air bags não é afetada pela informação a respeito da possibilidade de traição; 
$\mathrm{H}_{3}: \quad$ A preferência por air bags não é afetada em função do destinatário do produto.

\section{Coleta e Tratamento dos Dados}

A amostra do Estudo 2 - extraída por conveniência - foi composta por 146 estudantes de diversos cursos de uma instituição de ensino superior no Rio de Janeiro. Foram adotados os mesmos mecanismos de preservação do respondente em relação ao primeiro estudo.

Neste estudo, os participantes fizeram uma escolha entre dois automóveis idênticos equipados com air bags diferentes. As informações referentes a cada carro variavam de acordo com a condição experimentada por cada grupo:

- Grupo 1 (com traição; carro para uso próprio): o carro A apresenta, em caso de acidentes, uma chance de $2 \%$ de morte do motorista; o carro B, por sua vez, apresenta um risco de $1 \%$ de morte do motorista. Além disto, o carro B apresenta um risco adicional de 1 chance em 10.000 (0,01\%) do motorista morrer em decorrência de alguma falha no air bag;

- Grupo 2 (com traição; carro para desconhecidos): mesmas condições do Grupo 1;

- Grupo 3 (sem traição; carro para uso próprio): o carro A apresenta, em caso de acidentes, uma chance de $2 \%$ de morte do motorista; o carro B, por sua vez, apresenta um risco de $1 \%$ de morte do motorista;

- Grupo 4 (sem traição; carro para desconhecidos): mesmas condições do Grupo 3.

Os instrumentos de coleta de dados aplicados no Estudo 2 foram similares aos do Estudo 1. Diferiam somente pelo fato de indicar, antes da escolha pela Escala Likert, se o produto era para uso próprio ou para uso de terceiros. Os dados obtidos foram utilizados para a realização de uma ANOVA 2x2, cujos resultados estão descritos na próxima seção.

\section{Análise dos dados e apresentação dos resultados}

Os resultados da ANOVA 2x2 evidenciaram que a informação a respeito da possibilidade de traição interfere significativamente na escolha do tipo de air bag. Assim como no Estudo 1, a informação sobre a possibilidade de traição leva a um aumento na preferência pelo air bag menos seguro, implicando a rejeição da hipótese $\mathrm{H}_{2}(\mathrm{~F}(1,142)=16,400 ; p=0,000)$.

No entanto, os resultados indicaram que a escolha entre os air bags não é influenciada pelo tipo de destinatário, tanto no caso onde não há a evidência de traição $(F(1,142)=0,222 ; p=0,638)$ quanto no caso de evidência de traição $(F(1,142)=0,004, p=0,948)$, como mostra a Figura 2. Tais resultados impossibilitam a rejeição da hipótese $\mathrm{H}_{3}$.

Figura 2 . Preferência pela opção de air bag mais segura, de acordo com o destinatário e de acordo com a possibilidade de traição

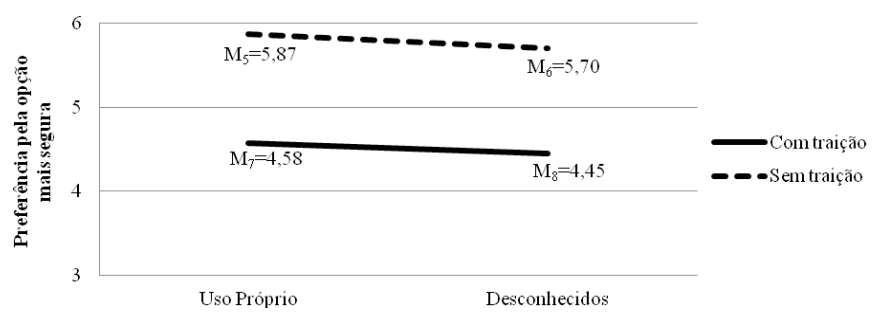

Concluiu-se que a possibilidade de traição leva os indivíduos a realizar uma escolha considerada irracional, optando pelo air bag menos seguro. Desta forma o Estudo 2, assim como o Estudo 1, evidenciou a existência da aversão à traição na escolha dos air bags. No entanto, o destinatário dos produtos não interferiu na escolha destes produtos.

Apesar de observada a aversão à traição neste estudo, seus resultados divergem parcialmente dos encontrados por Gershoff e Koehler (2011), visto que estes autores identificaram diferenças significativas na preferência do consumidor de acordo com o destinatário do produto. Isto pode ser explicado pelas diferenças culturais entre o Brasil e os Estados Unidos. Os americanos são notoriamente conhecidos por sua cultura individualista - como sugerido por Okigbo, Martin, e Amienyi (2005), de tal forma que é plausível que os americanos façam diferentes escolhas para si mesmos. Os brasileiros, por outro lado, apresentam um padrão cultural menos individualista, relacionado 
a um julgamento afetivo e um significado simbólico para um produto ou serviço. (TORRES; ALLEN, 2009). De acordo com Barros e Prates (1996) a população americana tem, dentre outras características, a de ser individualista, enquanto a brasileira seria mais relacional. Com base em diversos estudos, Chu e Wood Jr. (2008) corroboram tal afirmação ao defenderem que a cultura brasileira é considerada um pouco mais coletivista do que individualista. Além disso, os autores sugerem que se trata de uma cultura que possui alta necessidade de evitar incertezas, o que fica evidenciado nos resultados encontrados na presente pesquisa.

\section{Estudo 3 - Impacto de Campanhas de Direção Defensiva}

Raghunathan e Pham (1999) estudaram as influências motivacionais de ansiedade e tristeza na tomada de decisão, ressaltando que distinções entre estados negativos, muito presentes no cotidiano das pessoas - por exemplo, raiva, ansiedade, tristeza - costumam ser ignoradas em boa parte dos estudos. Gershoff e Koehler (2011) afirmam que riscos idênticos podem ser tratados de forma diferente devido a diferenças de sentimentos sobre as opções disponíveis ou sentimentos presentes no momento da avaliação. Assim, se um indivíduo assiste a um vídeo que provoque ansiedade logo antes de comprar um carro novo, é possível que ele mude suas preferências, optando por um carro mais seguro, no lugar de um carro mais potente ou luxuoso (GERSHOFF; KOEHLER, 2011; RAGHUNATHAN; PHAM, 1999).

Nesse sentido, Gershoff e Koehler (2011) argumentam que o tipo de imagem que acompanha a descrição de um dispositivo de segurança é um importante fator na escolha do produto, capaz de alterar avaliações baseadas em emoções e sentimentos (no caso da apresentação de imagens de apelos positivos) ou de evocar avaliações de caráter mais analítico.

De acordo com Poels e Dewitte (2006), o conceito de emoção tem sido interpretado como sinônimo de uma diversidade de reações. Sua classificação passa por um continuum cujos extremos interpretam: i) a emoção como reações espontâneas e incontroláveis (que não necessitam de muita ação cognitiva para ocorrer) ou ii) a emoção como algo que depende de forte processamento cognitivo do indivíduo e, neste caso, rotulada como emoção específica. Os autores indicam, entretanto, que estes dois extremos não são suficientes para interpretar todas as questões referentes à emoção, mas que gera uma base para discutir o tema.

Gershoff e Koehler (2011) apresentaram os resultados de um experimento que exibiu gráficos com números de mortes (relacionadas ou não com falhas em produtos para segurança) e apresentaram também os resultados de outro experimento no qual eram exibidas imagens que inspiravam tranquilidade _tal como a imagem de uma criança comendo melancia _ e imagens que inspiravam inquietações _ tal como a imagem de um cão mostrando os dentes ou de um assalto.

No presente artigo, seguindo a mesma lógica de apresentação de elementos visuais com apelos positivos e negativos, foi realizado outro experimento, envolvendo a exibição de duas propagandas relacionadas à direção defensiva (uma brasileira e uma irlandesa) para que, após assistirem às campanhas, as pessoas fizessem suas escolhas pelos modelos de air bags.

Há vários estudos que se dedicam à questão dos efeitos da propaganda nos consumidores em suas mais diversas formas. Bambauer-Sachse e Gierl (2009) investigaram se havia diferenças entre a percepção do consumidor quando este assiste propagandas com elementos nostálgicos ou sem elementos nostálgicos. Peacock et al. (2011) compararam propagandas de rádio e TV quanto à sua capacidade de gerar respostas emocionais e envolveros consumidores. MaieSchoeller (2009), por sua vez, verificaram experimentalmente o efeito da propaganda para os consumidores, avaliando suas emoções, atitudes, compreensão e memória, concluindo que as propagandas mais memoráveis foram as que evocaram os sentimentos mais positivos. Tais propagandas foram também melhor compreendidas pelos participantes do experimento. Para Hazlett e Hazlett (1999), a resposta emocional do expectador exerce influência nas escolhas dos indivíduos, tanto em relação aos comerciais de TV, quanto em relação a outros tipos de anúncios.

Além da proposta da exibição de propagandas ser coerente com a apresentação de apelos visuais, o uso de propagandas sociais, como é o caso das campanhas de direção defensiva, é muito comum quando se tem por objetivo gerar algum tipo de alteração comportamental nas pessoas (KOTLER; LEE, 2011; O'SHAUGHNESSY, 1996). 
Hawkins e Mothersbaugh (2010) observam que o fato de um indivíduo assistir a uma propaganda pode desencadear emoções. Assim, acredita-se que a exposição às emoções provocadas pelas campanhas pode impactar na escolha dos produtos. Adicionalmente, devido ao fato de as campanhas selecionadas apresentarem conteúdos bastante diferentes e uma ser considerada mais chocante do que a outra, acredita-se que a campanha brasileira tem potencial para influenciar na escolha de dispositivos para segurança em nível menor do que a campanha irlandesa poderia fazê-lo, visto que tende a despertar menos emoções, quando comparada à campanha irlandesa. Se confirmadas tais hipóteses, os resultados podem ser úteis para verificar reações dos consumidores quanto ao conteúdo das campanhas, o que foge ao escopo deste artigo, mas que pode ser relevante para pesquisas futuras.

As campanhas de direção defensiva escolhidas são descritas na Figura 3 a seguir:

Figura 3 . Descrição das campanhas utilizadas no Estudo 3

\begin{tabular}{|c|l|}
\hline Tipo de Campanha & \multicolumn{1}{c|}{ Descrição da Campanha } \\
\hline Campanha Leve & $\begin{array}{l}\text { A campanha "Pare e Pense 2011", apresentada pelo Departamento Nacional de Transito do Brasil } \\
\text { - DENATRAN (2011), possui a seguinte estrutura: carrinhos de brinquedos aparecem no primeiro } \\
\text { plano da filmagem, enquanto uma família está em casa e faz com a mão o sinal de Parada. Neste } \\
\text { momento, o narrador diz: "Está na hora de parar com a violência no trânsito". Enquanto três } \\
\text { pessoas atravessam uma rua e fazem sinal de Parada com a mão, o narrador diz: "Está na hora de } \\
\text { parar com as mortes de nossos jovens e crianças, vítimas de acidentes nas ruas e estradas". Um } \\
\text { jovem cadeirante também sinaliza com a mão que devemos parar, seguido de um motociclista } \\
\text { que faz o mesmo, enquanto o narrador diz: "Parar de dirigir em alta velocidade". Em seguida, } \\
\text { um grupo de pessoas em um bar, uma jovem, uma criança, todos sinalizando que devemos parar, } \\
\text { enquanto a narração continua informando: "Parar de dirigir depois de beber", "Parar com a falta de } \\
\text { respeito no trânsito". "Pare e pense, o respeito à vida depende de cada um de nós". }\end{array}$ \\
\hline Campanha Forte & $\begin{array}{l}\text { A campanha "The Faster The Speed, The Bigger The Mess", criada pela Autoridade de } \\
\text { Segurança Rodoviária da Irlanda - RSA (2007), apresenta a seguinte estrutura: um acidente } \\
\text { ocorre na estrada e um dos veículos envolvidos acaba por atingir um casal de namorados que } \\
\text { estava nas proximidades. Após mostrar todos os trágicos desdobramentos deste acidente - } \\
\text { incluindo mortes e diversos feridos - a campanha mostra que o acidente teve como gatilho a } \\
\text { imprudência de um dos motoristas, alertando os motoristas para os perigos da direção em alta } \\
\text { velocidade. }\end{array}$ \\
\hline
\end{tabular}

A Figura 4 exibe imagens pertencentes às campanhas em questão:

Figura 4 . Imagens pertencentes às campanhas "Pare e Pense 2011" e

"The Faster The Speed The Bigger The Mess", respectivamente

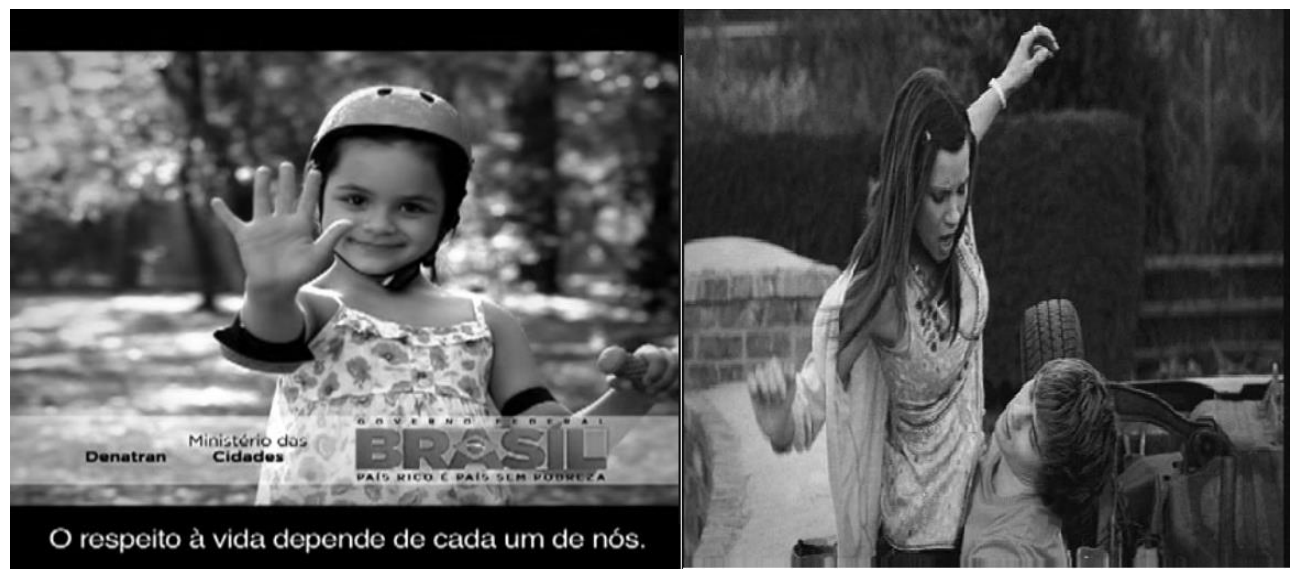

Fonte: DENATRAN (2011) e RSA(2007). 
A partir disto, as hipóteses que foram testadas no Estudo 3 foram:

$\mathrm{H}_{4}: \quad$ A preferência por air bags não é afetada pela exposição a campanhas de direção defensiva de impacto leve.

$\mathrm{H}_{5}: \quad$ A preferência por air bags não é afetada pela exposição a campanhas de direção defensiva de impacto forte.

\section{Coleta e Tratamento de Dados}

A amostra do Estudo 3 - extraída por conveniência - foi composta por 225 estudantes de diversos cursos de uma instituição de ensino superior de Minas Gerais. A definição do público jovem como universo da pesquisa, tanto para este estudo quanto para os estudos anteriores, se justifica pelas estatísticas de acidentes de trânsito, que indicam que os jovens até 25 anos são responsáveis por mais de $20 \%$ dos acidentes de trânsito no Brasil (DONATO, 2012). Foram adotados os mesmos mecanismos de preservação do respondente, em relação aos estudos anteriores.

Assim como nos estudos anteriores, os participantes do Estudo 3 foram questionados sobre a escolha entre dois carros idênticos, porém com air bags diferentes. Desta vez, os participantes foram divididos em seis grupos, de acordo com o tipo de exposição às campanhas e de acordo com o tipo de exposição à informação de traição:

- Grupo 1 (Com Traição; Sem campanha): os participantes não foram expostos à nenhuma das campanhas envolvidas napesquisa, sendo questionados a escolher entre o carro A, que apresenta uma chance de $2 \%$ de morte do motorista, e o carro B, que apresenta um risco de $1 \%$ de morte do motorista, além do risco adicional de 1 chance em 10.000 (0,01\%) do motorista morrer em decorrência de alguma falha no air bag;

- Grupo 2 (Com traição; Campanha Leve): os participantes foram expostos à Campanha Leve, sendo em seguida questionados a escolher entre o carro A, que apresenta uma chance de $2 \%$ de morte do motorista, e o carro B, que apresenta um risco de $1 \%$ de morte do motorista, além do risco adicional de 1 chance em $10.000(0,01 \%)$ do motorista morrer em decorrência de alguma falha no air bag;

- Grupo 3 (Com traição; Campanha Forte): os participantes foram expostos à Campanha Forte, sendo em seguida questionados a escolher entre o carro A, que apresenta uma chance de $2 \%$ de morte do motorista, e o carro $\mathrm{B}$, que apresenta um risco de $1 \%$ de morte do motorista, além do risco adicional de 1 chance em $10.000(0,01 \%)$ do motorista morrer em decorrência de alguma falha no air bag;

- Grupo 4 (Sem traição; Campanha Forte): os participantes foram expostos à Campanha Forte, sendo em seguida questionados a escolher entre o carro A, que apresenta uma chance de $2 \%$ de morte do motorista, e o carro B, que apresenta um risco de $1 \%$ de morte do motorista;

- Grupo 5 (Sem traição; Campanha Leve): os participantes foram expostos à Campanha Leve, sendo em seguida questionados a escolher entre o carro A, que apresenta uma chance de $2 \%$ de morte do motorista, e o carro $\mathrm{B}$, que apresenta um risco de $1 \%$ de morte do motorista;

- Grupo 6 (Grupo de Controle): os participantes não foram expostos a nenhuma das campanhas, bem como não foram expostos à informação sobre a possibilidade de traição, de forma que o carro A apresenta, em caso de acidentes, uma chance de $2 \%$ de morte do motorista, e o carro B, por sua vez, apresenta um risco de $1 \%$ de morte do motorista. Cabe ressaltar que este grupo de controle foi comparado ao Grupo de Controle do Estudo 1, a fim de identificar possíveis diferenças entre as populações observadas; 
Cabe ressaltar que, assim como nos estudos anteriores, o risco global do carro B $(1,01 \%)$ era menor em relação ao carro A $(2 \%)$, para todos os grupos observados. Deste modo, o instrumento de coleta de dados era idêntico ao utilizado no Estudo 1. Contudo, o respondente era exposto a um vídeo sobre direção defensiva antes de fornecer sua resposta.

Com base nos dados obtidos, foi realizada uma ANOVA $2 \times 3$ para identificar possíveis diferenças entre os grupos.

\section{Análise dos dados e apresentação dos resultados}

Os resultados da ANOVA $2 \times 3$ indicaram que a informação a respeito da possibilidade de traição interfere significativamente na escolha do tipo de air bag. Assim como nos dois estudos anteriores, a informação sobre a possibilidade de traição leva a um aumento na preferência pelo air bag menos seguro, contribuindo com a rejeição da hipótese $\mathrm{H}_{2}$ $(\mathrm{F}(2,219)=7,862 ; p=0,006)$, testada no Estudo 2 . Também foi encontrada uma interação significativa entre a exposição à campanha de direção defensiva e a exposição à informação de possibilidade de traição $(\mathrm{F}(2,219)=5,125 ; p=0,007)$. Esta interação sugere que a ocorrência destas condições de forma simultânea geraria resultados diferentes do que quando as mesmas ocorriam de forma isolada.

Testes adicionais para verificar o efeito desta interação indicaram que a exposição às campanhas de direção defensiva não afetavam a preferência do consumidor, quando os participantes não eram expostos à informação da possibilidade de traição $\mathrm{F}(2,106)=0,411$; $p=0,664)$. No entanto, quando expostos à informação da possibilidade de traição, a exposição à campanha de forte impacto afetava significativamente a preferência do consumidor por produtos de segurança, induzindo à escolha mais segura $(\mathrm{F}(2,113)=6,904 ; p=0,001)$. Por fim, os resultados indicavam que a exposição à campanha de leve impacto não afetava a preferência do consumidor $\mathrm{F}(1,143)=0,375 ; p=0,541)$. Estes resultados implicam a não-rejeição da hipótese $\mathrm{H}_{4}$ Quanto à hipótese $\mathrm{H}_{5}$, esta só pode ser rejeitada sob condições em que a possibilidade de traição é informada, como pode ser visto na Figura 5 a seguir:
Figura 5 . Preferência pela opção de air bag mais segura, de acordo com a exposição às campanhas de direção defensiva e de acordo com a exposição á informação de possibilidade de traição

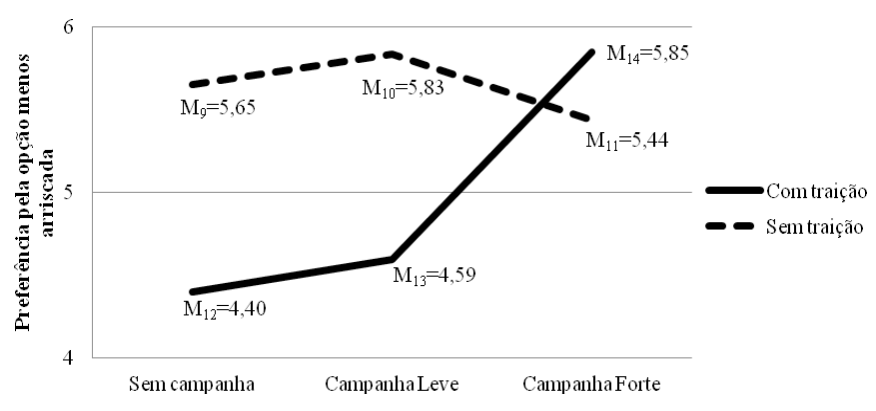

Os resultados deste estudo evidenciavam a existência de aversão à traição, quando os participantes eram expostos a esta situação. No entanto, a exposição a campanhas de forte impacto poderia reduzir tal aversão, levando o consumidor a escolher a opção mais segura. Estes resultados permitiram concluir que a aversão à traição pode ser reduzida, por meio de campanhas que impactem mais o consumidor.

\section{Considerações Finais}

Acredita-se que os resultados da pesquisa em questão neste artigo constituem um avanço no conhecimento acerca do comportamento do consumidor, especialmente quanto ao papel da emoção na tomada de decisão. A compreensão deste fenômeno é de grande importância para pesquisadores e profissionais de marketing que buscam identificar e compreender as emoções que cercam a tomada de decisão de um consumidor. Neste sentido, os resultados dos três estudos desta pesquisa, quando comparados com os obtidos por Gershoff e Koehler (2011), evidenciam que a aversão à traição é um fenômeno que também afeta os consumidores brasileiros de produtos de segurança. Aimone e Houser (2012) argumentam que tal aversão é uma resposta do indivíduo à violação de uma relação de confiança, visto que este certamente prefere evitar uma situação onde a traição pode ocorrer.

No entanto, determinadas características observadas por Gershoff e Koehler (2011) na aversão à traição não foram encontradas nos consumidores brasileiros. Enquanto os consumidores americanos apresentavam reações diferentes ao serem confrontados com diferentes formas de traição dos produtos de segurança, 
os consumidores brasileiros não apresentaram tal distinção em suas reações. Isto sugere que o consumidor brasileiro, independentemente do tipo de traição, reage da mesma forma, evitando as situações onde há a possibilidade de traição. Assim, as empresas que buscam reduzir a reação da aversão à traição no Brasil não deveriam se preocupar com especificidades relacionadas ao tipo de traição.

Além disso, os consumidores brasileiros não apresentaram reações distintas de acordo com o destinatário do produto. Aimone e Houser (2012) verificaram que a reação à possibilidade de traição pode ocorrer mesmo quando a traição não envolve o consumidor. No entanto, tais resultados divergem dos encontrados por Gershoff e Koehler (2011), que encontraram diferenças significativas nas respostas à traição de acordo com o destinatário do produto. A diferença entre os resultados de Gershoff e Koehler (2011) e os resultados desta pesquisa é possivelmente explicada por diferenças culturais entre os países investigados. Uma vez que o brasileiro é caracterizado como tendo uma cultura menos individualista, a questão do destinatário do produto torna-se menos significativo para as empresas que buscam reduzir a aversão à traição de seus consumidores.

Por fim, esta pesquisa verificou que campanhas de forte impacto podem levar os consumidores a reduzir sua aversão à possibilidade de traição dos produtos de segurança. Este resultado poderia subsidiar a forma pela qual as informações sobre as possibilidades de falha são repassadas ao consumidor. Campanhas publicitárias podem induzir o consumidor a priorizar o processamento racional das informações, levando-o a reduzir a aversão à traição e a tomardecisões consideradas mais seguras. Ao passo que os dois primeiros estudos buscaram identificar a existência da aversão à traição sob diversas formas, o terceiro estudo destacou-se por indicar um instrumento capaz de reduzir a aversão à traição, trazendo implicações gerenciais relevantes para a área de estratégia de marketing.

De forma geral, acredita-se que a pesquisa contribuiu para uma melhor compreensão do comportamento do consumidor brasileiro no que diz respeito à aversão à traição ao destacar um fenômeno ainda pouco observado na literatura brasileira sobre comportamento de consumo.

Uma questão que permanece sem resposta envolve as formas pelas quais os resultados desta pesquisa podem influenciar decisões gerenciais. Uma vez que a ausência da informação a respeito da possibilidade de traição pode levar a melhores resultados, como sugerido por Aimone e Houser (2012), a omissão de tal informação é defrontada por questões éticas: é ético omitir uma informação, visto que esta leva o consumidor a tomar uma decisão considerada ineficiente? Empresas podem tomar decisões equivocadas ao se deparar com tal questão e, buscando uma solução alternativa para o problema, a presente pesquisa sugere a não-omissão da informação, mas acompanhada de campanhas publicitárias que auxiliem o consumidor a lidar com a possibilidade de traição de forma racional, levando-o a uma tomada de decisão mais consciente e adequada.

Embora o artigo forneça importantes contribuições, também apresenta algumas limitações. Os participantes da pesquisa foram obtidos por meio de uma amostra coletada por conveniência, o que poderia gerar um viés de cobertura. Estudantes universitários de outras instituições, de outras regiões do país, poderiam ter comportamentos diferentes. Sugere-se que tal estudo seja replicado em outras regiões, a fim de corroborar os resultados aqui obtidos ou lançar luz sobre a necessidade de se rediscuti-los.

Além disso, apesar de verificar a aversão à traição nos consumidores brasileiros, e até mesmo revelar alguns possíveis instrumentos de redução deste fenômeno, a abordagem quantitativa utilizada não permitiu identificar os fatores responsáveis pela aversão à traição. Assim, sugerem-se pesquisas futuras que se utilizem de técnicas qualitativas, por meio da captação de opiniões detalhadas de pessoas avessas à traição objetivando um maior conhecimento acerca do que as pessoas pensam quando são informadas da possibilidade de traição. Com base na melhor identificação dos fatores responsáveis pela aversão à traição, poderiam ser desenvolvidos instrumentos mais precisos para reduzir a incidência deste fenômeno.

No que diz respeito ao efeito das campanhas publicitárias, Groeppel-Klein et al. (2010) afirmam que os métodos até agora utilizados para mensurar o impacto das emoções nas decisões têm limitações. Tais métodos podem ser verbais ou não verbais, como é o caso da apresentação de imagens, que requer muitos cuidados em sua escolha. Uma vez que os respondentes da presente pesquisa tiveram apenas um rápido contato com as campanhas publicitárias, foi possível capturar o efeito destas sobre as decisões tomadas 
pelos consumidores, mas não foi possível identificar a forma pela qual as emoções foram afetadas. Esta limitação, entretanto, constitui uma oportunidade para investigações futuras, possivelmente de caráter mais qualitativo.

Também com relação à venda de veículos, acredita-se que novas pesquisas que incluíssem entrevistas com montadoras ou concessionárias poderiam ser muito úteis para complementar e aprofundar os resultados apresentados neste artigo com vistas a desenvolver e administrar estratégias de vendas neste setor.

\section{Referências Bỉbliográficas}

AIMONE, J. A.; HOUSER, D. Beneficial betrayal aversion. PLoS ONE, 2011. v. 6, n. 3, p. 1-5.

. What you don't know won't hurt

you: a laboratory analysis of betrayal aversion.

Experimental Economics, 2012. v. 15, n. 4, p. 571-588.

. Harnessing the benefits of betrayal aversion. Journal of Economic Behavior \& Organization, maio. 2013. v. 89, p. 1-8.

ANDRADE, E. B.; ARIELY, D. The enduring impact of transient emotions on decision making. Organizational Behavior and Human Decision Processes, maio. 2009. v. 109, n. 1, p. 1-8.

BAMBAUER-SACHSE, S.; GIERL, H. Effects of nostalgic advertising through emotions and the intensity of the evoked mental images. Advances in Consumer Research, 2009. v. 36, p. 391-398.

BARROS, B. T. De; PRATES, M. A. S. O estilo brasileiro de administrar. São Paulo: Atlas, 1996.

BLACK, K. Business statistics for contemporary decision making. 6. ed. Hoboken: John Wiley \& Sons, 2009.

BOHNET, I. et al. Betrayal aversion: evidence from brazil, china, oman, switzerland, turkey, and the united states. American Economic Review, 2008. v. 98, n. 1, p. 294-310.

BORGHANS, L. et al. Gender differences in risk aversion and ambiguity aversion. Journal of the European Economic Association, 2009. v. 7, n. 2/3, p. 649-658.
CHU, J.; CHINTAGUNTA, P. K. An empirical test of warranty theories in the u.s. computer server and automobile markets. Journal of Marketing, 2011. v. 75, n. 2, p. 75-92.

CHU, R. A.; WOOD JR., T. Cultura organizacional brasileira pós-globalização: global ou local? Revista de Administração Pública, out. 2008. v. 42, n. 5, p. 969-991.

DEPARTAMENTO NACIONAL DE TRÂNSITO - DENATRAN. Campanha "pare e pense". [S.1.], 2011. Disponível em: < http://www.denatran.gov.br/ campanhas/show camp01.asp? cod $=087>$. Acesso em: 27 jan. 2013.

DOHMEN, T. et al. Are risk aversion and impatience related to cognitive ability? American Economic Review, 2010. v. 100, n. 3, p. 1238-1260.

DONATO, V. Maioria dos acidentes de trânsito no brasil é causada por jovens. Jornal Hoje, [S.l.], 20 set. 2012. Disponível em: <http://g1.globo.com/ jornal-hoje/noticia/2012/09/maioria-dos-acidentesde-transito-no-brasil-e-causada-por-jovens.html>. Acesso em: 21 jan. 2013.

DROLET, A.; LUCE, M. F. The rationalizing effects of cognitive load on emotion based trade off avoidance. Journal of Consumer Research, 2004. v. 31, n. 1, p. 63-77.

EPSTEIN, S. Integration of the cognitive and the psychodynamic unconscious. American Psychologist, 1994. v. 49, n. 8, p. 709-724. Individual differences in intuitiveexperiential and analytical-rational thinking styles. Journal of Personality and Social Psychology, 1996. v. 71, n. 2, p. 390-405.

FARO, D.; ROTTENSTREICH, Y. Affect, empathy, and regressive mispredictions of others' preferences under risk. Management Science, 2006. v. 52, n. 4, p. 529-541.

GERSHOFF, A. D.; KOEHLER, J. J. Safety first? the role of emotion in safety product betrayal aversion. Journal of Consumer Research, 2011. v. 38, n. 1, p. $140-150$.

GROEPPEL-KLEIN, A. et al. Measurement of emotions elicited by advertising. Advances in Consumer Research, 2010. v. 37, p. 497-498. 
HAWKINS, D. I.; MOTHERSBAUGH, D. L.

Consumer behavior: building marketing strategy. 11. ed. Boston: McGraw-Hill Irwin, 2010.

HAZLETTT, R. L.; HAZLETT', S. Y. Emotional response to television commercials: facial emg vs. self-report. Journal of Advertising Research, 3 abr. 1999. v. 39, n. 2, p. 7-23.

KAHNEMAN, D.; TVERSKY, A. Prospect theory: an analysis of decision under risk. Econometrica, 1 mar. 1979. v. 47, n. 2, p. 263-291.

KOEHLER, J. J.; GERSHOFF, A. D. Betrayal aversion: when agents of protection become agents of harm. Organizational Behavior and Human Decision Processes, 2003. v. 90, n. 2, p. 244-261.

KOTLER, P.; LEE, N. Marketing social: influenciando comportamentos para o bem. 3 . ed. Porto Alegre: Bookman, 2011.

MAI, L.-W.; SCHOELLER, G. Emotions, attitudes and memorability associated with tv commercials.

Journal of Targeting, Measurement \& Analysis for Marketing, 2009. v. 17, n. 1, p. 55-63.

MALHOTRA, N. Pesquisa de marketing. uma orientação aplicada. 6 ed. ed. Porto Alegre: Bookman, 2011.

MEYER, M. C.; FINNEY, T. Who wants airbags? Chance, 2005. v. 18, n. 2, p. 03-15.

MORRISON, E. W.; ROBINSON, S. L. When employees feel betrayed: a model of how psychological contract violation develops. The

Academy of Management Review, 1997. v. 22, n. 1, p. 226-256.

OKIGBO, C.; MARTIN, D.; AMIENYI, O. P. Our ads 'r us: an exploratory content analysis of american advertisements. Qualitative Market Research: An International Journal, 2005. v. 8, n. 3, p. 312-326.

O'SHAUGHNESSY, N. Social propaganda and social marketing: a critical difference? European Journal of Marketing, 1996. v. 30, n. 10/11, p. 62-75.

PEACOCK, J.; PURVIS, S.; HAZLETT, R. L. Which broadcast medium better drives engagement? Journal of Advertising Research, 2011. v. 51, n. 4, p. 578-585.
PRENTICE, R. A.; KOEHLER, J. J. A normality bias in legal decision making. Cornell Law Review, 2003. v. 88 , p. 583.

RAGHUNATHAN, R.; PHAM, M. T. All negative moods are not equal: motivational influences of anxiety and sadness on decision making. Organizational Behavior and Human Decision Processes, 1999. v. 79, n. 1, p. 56-77.

REMENYI, D. et al. Doing research in business and management: an introduction to process and method. London: SAGE, 1998.

ROAD SAFETY AUTHORITY - RSA. The faster the speed, the bigger the mess. [S.l.], 2007. Disponível em: < http://www.rsa.ie/en/RSA/RoadSafety/Campaigns/Archived-Campaigns/Mess-Crash/>. Acesso em: 27 jan. 2013.

ROSELIUS, R. Consumer rankings of risk reduction methods. Journal of Marketing, 1971. v. 35, n. 1, p. 56-61.

ROTTENSTREICH, Y.; KIVETZ, R. On decision making without likelihood judgment. Organizational Behavior and Human Decision Processes, 2006. v. 101, n. 1, p. 74-88.

SLOMAN, S. A. The empirical case for two systems of reasoning. Psychological Bulletin, 1996. v. 119, n. 1, p. 03-22.

SLOVIC, P. et al. Affect, risk and decision making. Health Psychology, 2005. v. 24, n. 4 (Suppl), p. S35-S40.

SLOVIC, P.; PETERS, E. Risk perception and affect. Current Directions in Psychological Science, 2006. v. 15, n. 6, p. 322-325.

SUNSTEIN, C. R. Moral heuristics. Behavioral and Brain Sciences, 2005. v. 28, n. 04, p. 531-542.

TORRES, C. V.; ALLEN, M. W. Influência da cultura, dos valores humanos e do significado do produto na predição de consumo: síntese de dois estudos multiculturais na austrália e no brasil.

Revista de Administração Mackenzie, 2009. v. 10, n. 3 . 